\title{
Immunological effects of the anti-programmed death-1 antibody on human peripheral blood mononuclear cells
}

\author{
YASUTO AKIYAMA ${ }^{1,2^{*}}$, CHIZU NONOMURA ${ }^{1}$, RYOTA KONDOU ${ }^{1}$, HARUO MIYATA ${ }^{1}$, TADASHI ASHIZAWA ${ }^{1}$, \\ CHIE MAEDA $^{1}$, KOICHI MITSUYA ${ }^{2}$, NAKAMASA HAYASHI ${ }^{2}$, YOKO NAKASU ${ }^{2}$ and KEN YAMAGUCHI ${ }^{3}$ \\ ${ }^{1}$ Immunotherapy Division, Shizuoka Cancer Center Research Institute, ${ }^{2}$ Division of Neurosurgery, \\ ${ }^{3}$ Office of The President, Shizuoka Cancer Center Hospital, Nagaizumi-cho, Sunto-gun, Shizuoka 411-8777, Japan
}

Received April 15, 2016; Accepted May 30, 2016

DOI: $10.3892 /$ ijo.2016.3586

\begin{abstract}
Immune checkpoint antibody-mediated blockade has gained attention as a new cancer immunotherapy strategy. Accumulating evidence suggests that this therapy imparts a survival benefit to metastatic melanoma and non-small cell lung cancer patients. A substantial amount of data on immune checkpoint antibodies has been collected from clinical trials; however, the direct effect of the antibodies on human peripheral blood mononuclear cells (PBMCs) has not been exclusively investigated. In this study, we developed an anti-programmed death-1 (PD-1) antibody (with biosimilarity to nivolumab) and examined the effects of the antibody on PBMCs derived from cancer patients. Specifically, we investigated the effects of the anti-PD-1 antibody on proliferation, cytokine production, cytotoxic $\mathrm{T}$ lymphocytes (CTL) and regulatory $\mathrm{T}$ cells. These investigations yielded several important results. First, the anti-PD-1 antibody had no obvious effect on resting PBMCs; however, high levels of the anti-PD-1 antibody partly stimulated PBMC proliferation when accompanied by an anti-CD3 antibody. Second, the anti-PD-1 antibody restored the growth inhibition of anti-CD3 Ab-stimulated PBMCs mediated by PD-L1. Third, the anti-PD-1 antibody exhibited a moderate inhibitory effect on the induction of myeloid-derived suppressor cells (MDSCs) by anti-CD3 antibody stimulation. Additionally, the presence of the anti-PD-1 antibody promoted antigen-specific CTL induction, which suggests that combining anti-PD-1 antibody and conventional immuno-
\end{abstract}

Correspondence to: Dr Yasuto Akiyama, Immunotherapy Division, Shizuoka Cancer Center Research Institute, 1007 Shimonagakubo, Nagaizumi-cho, Sunto-gun, Shizuoka 411-8777, Japan

E-mail: y.akiyama@scchr.jp

Abbreviations: CTL, cytotoxic T lymphocytes; CTLA-4, cytotoxic T-lymphocyte-associated antigen-4; DC, dendritic cell; MDSC, myeloid-derived suppressor cell; PBMC, peripheral blood mononuclear cell; PD-1, programmed death-1; Treg, regulatory T cells

Key words: checkpoint antibody, anti-PD-1 antibody, human peripheral blood mononuclear cell, regulatory $\mathrm{T}$ cells, myeloid-derived suppressor cell therapy treatments may have beneficial effects. These results indicate that specific cellular immunological mechanisms are partly responsible for the antitumor effect exhibited by the anti-PD-1 antibody against advanced cancers in clinical trials.

\section{Introduction}

In recent years, a novel type of cancer immunotherapy has arisen that involves a specific monoclonal antibody (mAb) targeting immune checkpoint molecules, such as cytotoxic T-lymphocyte-associated antigen-4 (CTLA-4) and the programmed death-1 (PD-1) receptor/PD-ligand 1 (PD-L1) interaction. This type of therapy has been applied in many clinical trials (1-5). The mechanisms responsible for the antitumor activity of immune checkpoint blockade are thought to involve a restoration of $\mathrm{T}$ cell suppression mediated by tumors (6-8). The PD-1 and CTLA-4 pathways have different roles in regulating $\mathrm{T}$ cell activity; CTLA-4 is involved in the priming T-cell phase by interacting with antigen-presenting cells (APC) expressing co-stimulatory molecules and PD-1 is involved in the effector $\mathrm{T}$ cell phase by blocking cancer cells expressing PD-L1 (9).

Ipilimumab is an anti-CTLA-4 mAb, and nivolumab is an anti-PD-1 mAb; these antibodies were approved by the FDA in 2011 and 2014, respectively, for treating metastatic and unresectable melanomas. The first phase I clinical trial for nivolumab involved 296 patients and reported that the objective response rates was 17,32 and $29 \%$ for advanced non-small cell lung cancers (NSCLC), melanoma and renal cell carcinoma (RCC), respectively, all of which had been treated heavily prior to the study (3). Additionally, nivolumab demonstrated an overall survival improvement over dacarbazine in a phase III study on previously untreated metastatic melanoma patients (10).

Despite the clinical trial success with nivolumab against advanced cancers, few preclinical studies have focused on PD-1 mAb. There are several reasons for this lack of preclinical studies: i) mouse systems cannot accurately represent the human immune response induced by the antiPD-1 mAb, and ii) few efficient mouse anti-PD-1 antibodies are available. Currently, only a few in vivo studies have been published that used mouse tumor cells and mouse anti-PD-1 antibodies and that verified the antitumor response and 
specific CTL induction $(11,12)$. However, there are difficulties associated with replacing the mouse immune system with a human system-like and then predicting the clinical response in humans from those mouse in vivo studies. In the future, the antitumor effect of the anti-PD-1 antibody may be investigated in a humanized mouse system that uses human immune cells and tumor cells.

In this study, we manufactured an in-house anti-PD-1 $\mathrm{mAb}$ that is similar to nivolumab, and we investigated the immunological effect of the antibody on the peripheral blood mononuclear cells (PBMCs) of cancer patients. We obtained specific in vitro immunological data by treating PBMCs with anti-PD-1 mAb. These results may contribute to the profiling of patients to predict which patients are likely to respond to anti-PD-1 mAb.

\section{Materials and methods}

Cancer patient-derived PBMCs. PBMCs from malignant glioma patients were used for in vitro experiments. The studies involving PBMCs derived from glioma patients were approved by the Institutional Review Board of Shizuoka Cancer Center, Shizuoka, Japan. All patients gave written informed consent. PBMCs from 6 glioma patients were used for in vitro cell-based assay (Table I).

Antibodies and reagents. The following antibodies were used for flow cytometric analyses: anti-CD3-PerCP, anti-CD4-PE, anti-CD8-FITC, anti-CD11b-PE-Cy7, anti-CD14-PE, anti-CD19-FITC, anti-CD25-FITC, anti-CD33-FITC, anti-CD45RO-PE, anti-CD56-biotin, anti-CCR7-biotin, anti-FoxP3-PE, anti-PD-1-APC, anti-PD-L1-APC and anti-human IFN- $\gamma$-PE. Anti-PD-1-APC and anti-PD-L1-APC antibodies were purchased from BioLegend Inc. (San Diego, CA, USA). All other antibodies were purchased from BD Pharmingen (San Diego, CA, USA). No azide/low endotoxin (NA/LE) anti-CD3 mAb was also purchased from BD Pharmingen and used for in vitro stimulation of human PBMCs. The WST-1 assay reagent was purchased from Dojin Kagaku Corp. (Kumamoto, Japan) and was used for cell proliferation assay. Human recombinant PD-L1 and PD-1 proteins were purchased from Sino Biotechnology (BDA, Beijing, China), and were used for a blocking assay with the anti-PD-1 mAb and for surface plasmon resonance (SPR) analysis, respectively. Commercially available unconjugated anti-PD-1 mAb was purchased from BioLegend Inc. and used for SPR assay.

Production and purification of the in-house full-length anti-PD-1 monoclonal antibody. The amino acid sequence of nivolumab was downloaded from the J-PlatPat data base from National Center for Industrial Property Information and Training (INPIT) (https://www.j-platpat.inpit.go.jp/web/tokujitsu/tkbs/TKBS_GM401_ToPDF.action). Nivolumab-derived $\mathrm{VH}$ and VL genes were synthesized according to their cDNA sequences and were cloned into a pcDNA3.3 vector for $\operatorname{IgH}$ and IgL co-expressions. Specifically, the VH gene was ligated with human IgG4 fragment that was PCR-cloned from the human PBMC-derived cDNA, and the product was finally inserted into pcDNA3.3. These IgH and IgL vectors were expanded, purified by endotoxin-depletion and co-transduced into
Table I. The characteristics of high-grade glioma patients.

\begin{tabular}{lcccl}
\hline Patient code & Age & Gender & HLA-typing & Pathology \\
\hline GB-001 & 45 & M & A2 & GBM (IV) \\
GB-002 & 37 & M & A2 & AA (III) \\
GB-003 & 53 & M & A24 & GBM (IV) \\
GB-004 & 63 & F & A2 & GBM (IV) \\
GB-005 & 56 & M & A24 & GB (IV) \\
GB-006 & 71 & M & A2 & GBM (IV) \\
\hline
\end{tabular}

GBM, glioblastoma multiforme; AA, anaplastic astrocytoma. ${ }^{a} \mathrm{WHO}$ pathological grade.

expi293 cells using lipofection according to the manufacturer's instructions. The supernatant was harvested and affinitypurified with a protein A prepacked column (GE Healthcare). Finally anti-PD-1 mAb was purified as a biosimilar antibody to nivolumab and was used for in vitro experiments.

Surface plasmon resonance (SPR) analysis using an in-house full-length anti-PD-1 monoclonal antibody. SPR analysis was performed on a Biacore X100 (GE Healthcare) as reported previously (15). All reagents and sensor chips were purchased from GE Healthcare. Immobilization of anti-human IgG antibody was performed at $\mathrm{pH} 5.0$ on the CM5 sensor chip for capturing anti-PD-1 antibody as ligand, and the amount targeted was 1,000 response units (RU). The analyte was a recombinant human PD-1 protein. Commercially available anti-PD-1 mAb was purchased from BioLegend (clone EH12.2H7) and monitored as a control.

Cell proliferation assay. Cell proliferation was examined using the WST-1 assay (Dojin Kagaku Corp., Kumamoto, Japan). Briefly, 1-2 $\times 10^{5}$ PBMCs were seeded into each well of a 96-well micro-culture plate coated with anti-CD3 mAb at $5 \mu \mathrm{g} / \mathrm{ml}$ overnight at $4^{\circ} \mathrm{C}$. Anti-PD- $1 \mathrm{mAb}$ was added at various concentrations and cells were cultured for 5 days. The WST-1 substrate was added to the culture, and the optical density (OD) was measured at 450 and $620 \mathrm{~nm}$ using an immunoreader (Immuno Mini NJ-2300, Nalge Nunc International, Roskilde, Denmark).

For the PD-L1 blocking assay, the anti-PD-1 mAb and the PD-L1 recombinant protein were sequentially added to a 96-well plate experiment. After a 5-day culture, the cell proliferation assay was performed using a WST-1 reagent.

Human PBMC cultures stimulated with anti-CD3 for FACS analysis. A 6-well culture plate was coated with NA/LE anti-CD3 $\mathrm{mAb}$ at $5 \mu \mathrm{g} / \mathrm{ml}$ at $4^{\circ} \mathrm{C}$ overnight. Human PBMCs were seeded at $8 \times 10^{6}$ per well in $4 \mathrm{ml}$ of RPMI-1640 medium (Sigma-Aldrich, St. Louis, MO, USA) supplemented with L-glutamine $(2 \mathrm{mM})$, penicillin $(100 \mathrm{U} / \mathrm{ml})$, streptomycin $(100 \mathrm{U} / \mathrm{ml})$ and $10 \%$ fetal bovine serum (FBS, Gibco, Paisley, UK). After $1 \mathrm{~h}$, anti-PD-1 mAb was added at various concentrations and cells were cultured for 5 days. Then, FACS analysis was performed to analyze the T cell markers, myeloid-derived suppressor cells (MDSCs) and IFN- $\gamma$ production. 


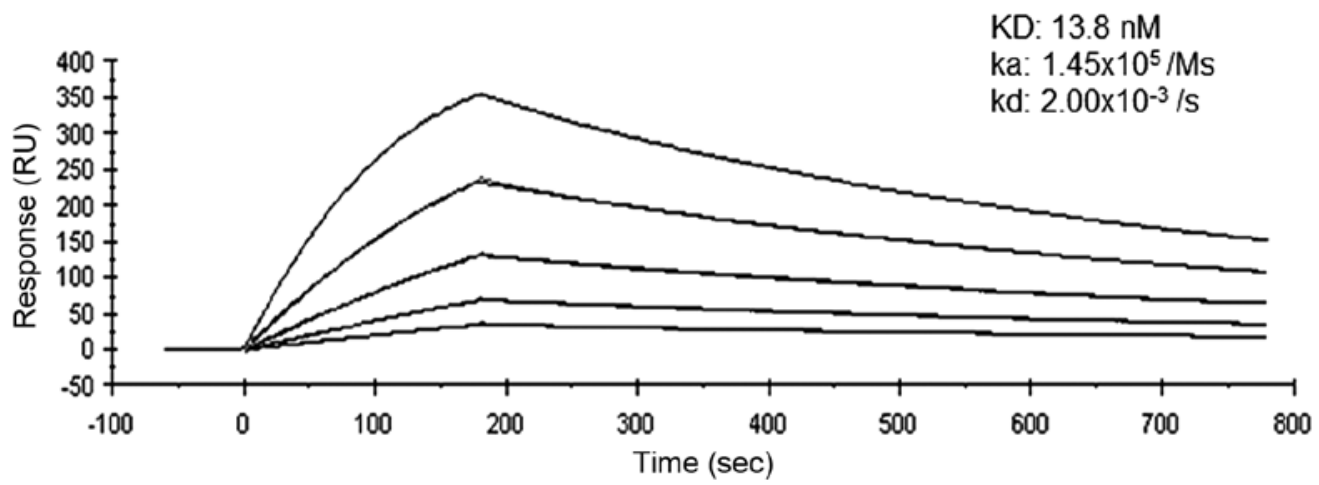

Figure 1. Determination of the affinity dynamics of a biosimilar anti-PD-1 mAb. SPR analysis of anti-PD-1 mAb binding to recombinant human PD-1 protein was performed. Binding dynamics were monitored and calculated using a Biacore X100. Anti-PD-1 mAb purchased from BioLegend (clone EH12.2H7) was monitored as a control.

For the PD-L1 blocking assay, 30 min after the addition of anti-PD-1 mAb, PD-L1 recombinant protein was added for a final concentration of $10 \mu \mathrm{g} / \mathrm{ml}$ in a 6 -well culture plate and cells were cultured for 5 days. For MDSC induction analysis, $\mathrm{CD} 33^{+} \mathrm{CD} 11 \mathrm{~b}^{+} \mathrm{MDSC}$ and $\mathrm{CD} 14^{+} \mathrm{CD} 11 \mathrm{~b}^{+}$monocyte MDSC fractions were measured using a flow cytometry. In the case of IFN- $\gamma$ production analysis, after 5-day cultures with or without anti-PD-1 mAb and PD-L1, cells were stimulated with PMA (Sigma-Aldrich Corp., St. Louis, MO, USA) and ionomycin (Sigma) for $4 \mathrm{~h}$. Finally, FACS analysis was performed to measure IFN- $\gamma^{+} \mathrm{T}$ cells using intracellular staining with anti-human IFN- $\gamma$-PE antibody.

Propidium iodide (PI) was used for detecting living cells. Cell suspensions were harvested from cultured PBMCs and were stained with various primary antibodies for $15 \mathrm{~min}$ at $4^{\circ} \mathrm{C}$ and then washed with cold PBS $+2 \%$ fetal bovine serum (FBS; Life Technologies). Then, cells were stained with the secondary antibodies for $15 \mathrm{~min}$ at $4^{\circ} \mathrm{C}$. After washing, cells were fixed with $0.5 \%$ paraform aldehyde-containing PBS (-) and analyzed on a FACSCanto II flow cytometer (BD Biosciences, San Diego, CA, USA).

Peptide-pulsed dendritic cell (DC)-based CTL induction assay using tetramer staining. CTL induction cultures were described previously (13). Immature DCs were induced by GM-CSF and IL-4, and mature type-1 DCs were induced by a combination of cytokines, as reported previously (14). HLA-A2-positive PBMCs derived from four glioma patients were used for CTL induction assay. Mature DCs were pulsed with HLA-A2-restricted MART-1, GP100 or CMVpp65 peptide and used for CTL induction cultures. An isotype control antibody or anti-PD-1 mAb was added to CTL cultures at a concentration of $10 \mu \mathrm{g} / \mathrm{ml}$. Two-rounds of co-culture of $\mathrm{T}$ cells and DCs were performed, and $\mathrm{CD} 8^{+}$tetramer ${ }^{+}$cells fraction was measured using flow cytometry. More than $0.1 \%$ of $\mathrm{CD}^{+}{ }^{+}$tetramer ${ }^{+}$cell frequency was rated as positive after treatment with anti-PD-1 Ab. The tetramers for MART-1, GP100 and CMVpp65 antigens were HLA-A2 restricted, and HIV-tetramer was HLA-A24 restricted.

Regulatory $T$ cell induction assay. During two-rounds of co-culture, $\mathrm{T}$ cells and mature DCs were treated with or without anti-PD-1 $\mathrm{mAb}$ at a concentration of $10 \mu \mathrm{g} / \mathrm{ml}$ in 6-well culture plate, cells were collected and used also for Treg induction analysis. $\mathrm{CD} 4{ }^{+} \mathrm{CD} 25^{+}$fraction was gated and $\mathrm{FoxP}^{+}$cells were measured using flow cytometry.

Statistical analysis. The significance of differences was analyzed using Student's t-test. Values of $\mathrm{P}<0.05$ were considered statistically significant.

\section{Results}

Binding affinity of anti-PD-1 $m A b$ to recombinant $P D-1$. SPR analysis confirmed the affinity of anti-PD-1 mAb to recombinant PD-1 consistently and mean dissociation constants were determined to be $13.8 \mathrm{nM}$ (Fig. 1). The binding affinity of anti-PD-1 mAb was greater than that of the commercially available anti-PD-1 antibody (98.9 $\mathrm{nM})$, as judged by SPR analysis (data not shown).

Effect of anti-PD-1 mAb on PBMC proliferation stimulated by the anti-CD3 antibody. Anti-PD-1 $\mathrm{mAb}$ showed no stimulatory activity on resting human PBMCs. However, high concentration of anti-PD-1 mAb exhibited moderate stimulatory effect on CD3 antibody-stimulated PBMCs from 2 of 6 patients (Fig. 2).

Effect of anti-PD-1 $m A b$ on $T$ cell subsets in anti-CD3 antibody-stimulated PBMC. The anti-PD-1 mAb showed no significant effect on the percentage $(\%)$ of $\mathrm{CD}^{+} \mathrm{CD} 4^{+}$ and $\mathrm{CD}^{+} \mathrm{CD}^{+}$subpopulations in anti-CD3 Ab-stimulated PBMCs. Additionally, the percentage (\%) of effector memory $\mathrm{T}$ cell subsets such as $\mathrm{CD} 4{ }^{+} \mathrm{CD} 45 \mathrm{RO}^{+} \mathrm{CD} 95^{+} \mathrm{CCR} 7{ }^{-}$were not affected by anti-PD-1 mAb (Table II).

Effect of PD-L1-inhibited PBMC proliferation and IFN- $\gamma$ production by anti-PD-1 $m A b$. PD-L1 at $10 \mu \mathrm{g} / \mathrm{ml}$ significantly suppressed the anti-CD3 Ab-stimulated PBMC proliferation (Fig. 3). The addition of anti-PD-1 mAb at concentration $>10 \mu \mathrm{g} / \mathrm{ml}$ restored the growth inhibition, and interestingly at $20 \mu \mathrm{g} / \mathrm{ml}$ anti-PD-1 mAb surpassed the control growth level (in the absence of PD-L1). On the other hand, IFN- $\gamma$ production measured by intracellular staining showed a tendency of 

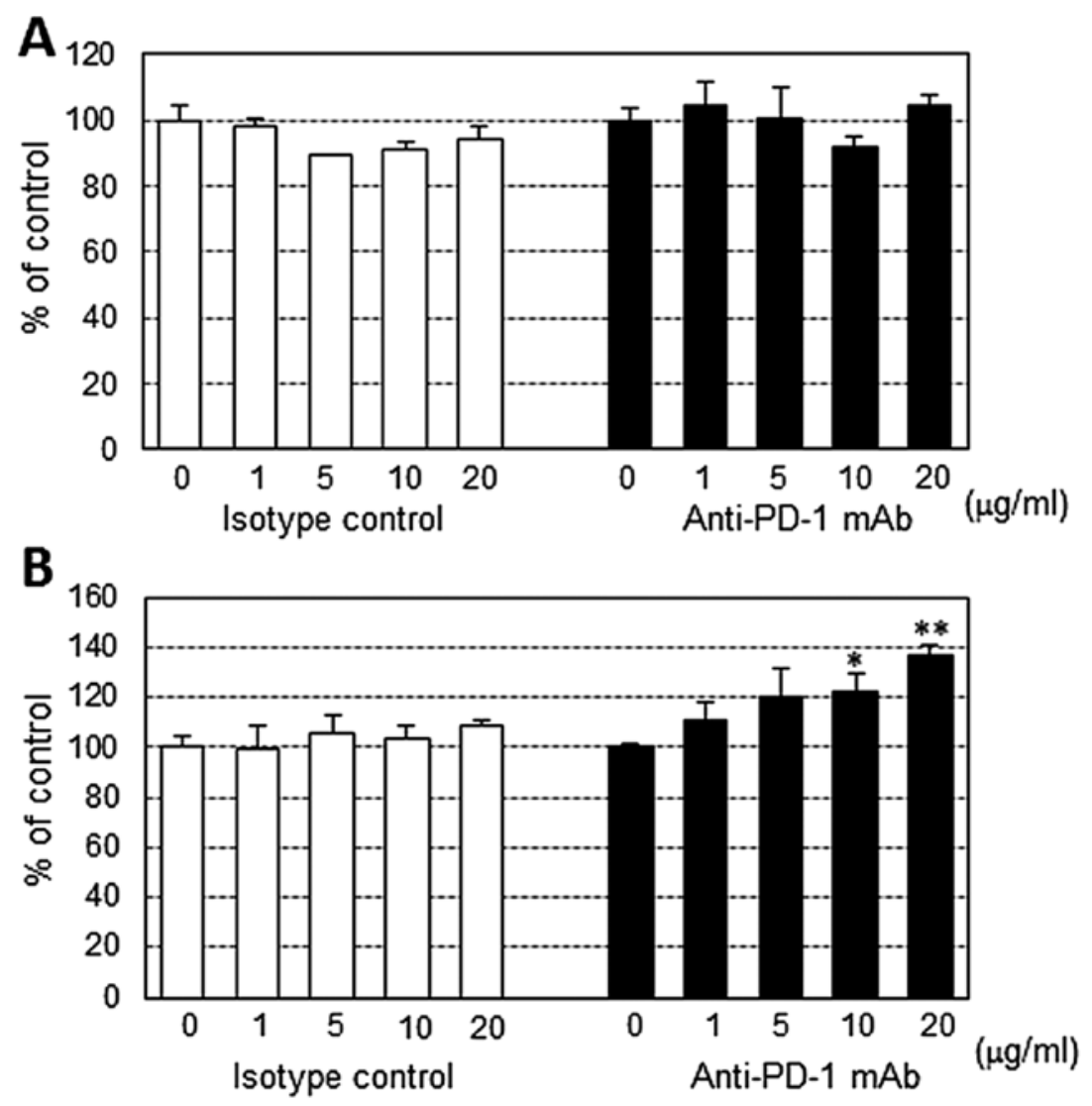

Figure 2. Effect of the anti-PD-1 mAb on anti-CD3 Ab-stimulated PBMC proliferation. Effect of anti-PD-1 mAb on (A) resting PBMCs and (B) anti-CD3 $\mathrm{Ab}$-stimulated PBMCs was analyzed. Control or anti-PD-1 mAb was used at concentrations ranging from 1 to $20 \mu \mathrm{g} / \mathrm{ml}$. Each graph shows a representative case from 6 sets of glioma patient-derived PBMCs, and each column indicates the mean \pm SD of triplicate tests. ${ }^{*} \mathrm{P}<0.05,{ }^{* *} \mathrm{P}<0.01$, statistically significant.

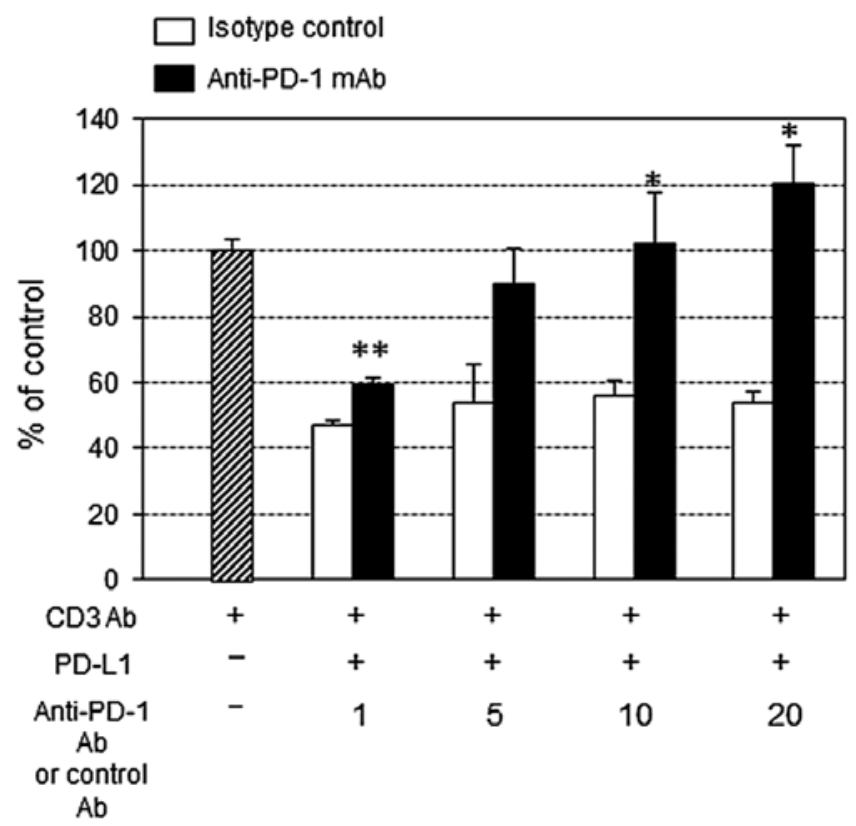

Figure 3. Blocking activity of anti-PD-1 mAb against soluble PD-L1mediated $\mathrm{T}$ cell growth-inhibition. The recombinant soluble PD-L1 protein was used at $10 \mu \mathrm{g} / \mathrm{ml}$ and anti-PD-1 $\mathrm{mAb}$ was used at concentrations ranging from 1 to $20 \mu \mathrm{g} / \mathrm{ml}$. The graph shows a representative case from 6 sets of glioma patient-derived PBMCs, four of which demonstrated a recovery from PD-L1-induced T cell inhibition. Each column indicates the mean \pm SD of triplicate tests. Open column, isotype control Ab; closed column, anti-PD-1 $\mathrm{mAb}$; shaded column, no PD-L1 and no anti-PD-1 mAb. ${ }^{*} \mathrm{P}<0.05,{ }^{* *} \mathrm{P}<0.01$, statistically significant. restoration in anti-PD-1 mAb compared to isotype control cultures containing PD-L1, however it was not statistically significant (Fig. 4).

Effect of anti-PD-1 mAb on MDSC induction. A small number of $\mathrm{CD}_{3} 3^{+} \mathrm{CD} 11 \mathrm{~b}^{+} \mathrm{MDSC}$ and $\mathrm{CD} 14^{+} \mathrm{CD} 11 \mathrm{~b}^{+}$monocyte MDSCs were identified in anti-CD3 antibody-stimulated PBMC cultures. The addition of anti-PD-1 mAb inhibited monocyte MDSC induction by $\sim 40 \%$ compared to the control (Fig. 5A and B). PD-L1 expression was observed in $60 \%$ of $\mathrm{CD}_{3}{ }^{+} \mathrm{CD}_{11 b^{+}} \mathrm{MDSCs}$; however, anti-PD-1 mAb did not show significant effects on PD-L1 expression (Fig. 5C).

Stimulatory effect of anti-PD-1 mAb on antigen-specific CTL induction. Antigen peptide (MRAT-1, GP100, CMVpp65)specific CTLs with HLA-A2 restriction significantly increased in anti-PD-1 Ab-treated CTL cultures compared to control Ab-treated cultures (Fig. 6A and B and Table III). In contrast, no CTLs responded to HLA-A24-restricted HIV peptide. Interestingly, mature DCs demonstrated higher PD-L1 expression than immature DCs (Fig. 6D).

Effect of anti-PD-1 mAb on Treg induction. Regulatory T cell induction was investigated after two-rounds of CMVpp65 peptide-pulsed DC-mediated CTL stimulation. The frequency of $\mathrm{CD} 4{ }^{+} \mathrm{CD} 25^{+}$fraction was not different between control and anti-PD-1 Ab treated cultures. However, the frequency of 
Table II. Effect of anti-PD-1 antibody on T cell subsets in PBMCs.

\begin{tabular}{lcccc}
\hline $\begin{array}{l}\text { Anti-PD-1 Ab } \\
(\mu \mathrm{g} / \mathrm{ml})\end{array}$ & $\mathrm{CD}^{+}$ & $\begin{array}{c}\text { T cell marker }(\%) \\
\mathrm{CD}^{+} \mathrm{CD}^{+}\end{array}$ & $\mathrm{CD}^{+} \mathrm{CD}^{+}$ & $\begin{array}{c}\text { Memory T cell marker }(\%) \\
\mathrm{CD}^{+} \mathrm{CD}^{+} \text {45O }{ }^{+} \mathrm{CD} 95^{+} \mathrm{CCR}^{-\mathrm{a}}\end{array}$ \\
\hline 0 & $80.4 \pm 6.5$ & $59.7 \pm 20.3$ & $24.1 \pm 17.1$ & $17.1 \pm 2.8$ \\
10 & $83.4 \pm 7.5$ & $60.9 \pm 16.4$ & $26.8 \pm 10.2$ & $20.8 \pm 1.5$ \\
20 & $82.3 \pm 3.3$ & $64.7 \pm 18.2$ & $27.1 \pm 14.9$ & $23.3 \pm 3.1$ \\
\hline
\end{tabular}

${ }^{\mathrm{a}} \mathrm{CD} 4+$ fraction was gated and specific memory $\mathrm{T}$ cell subset was measured. Each value shows mean \pm SD of PBMC data derived from 6 glioma patients.

A

IFN- $\gamma$

Control $\mathrm{Ab}$
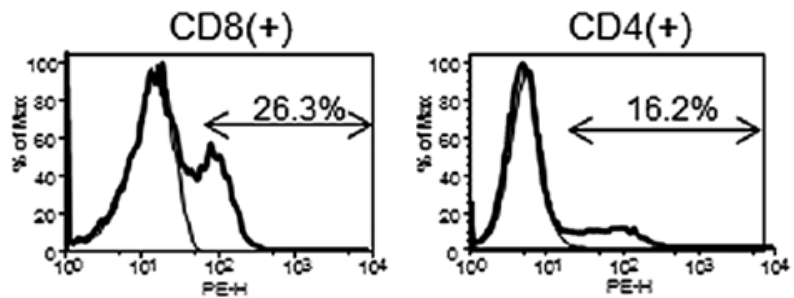

Anti-PD-1 Ab
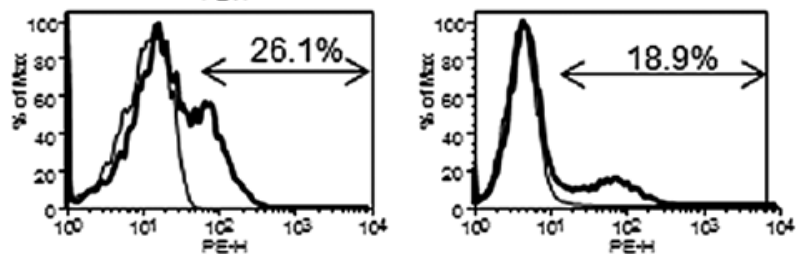

Control Ab + sPD-L1
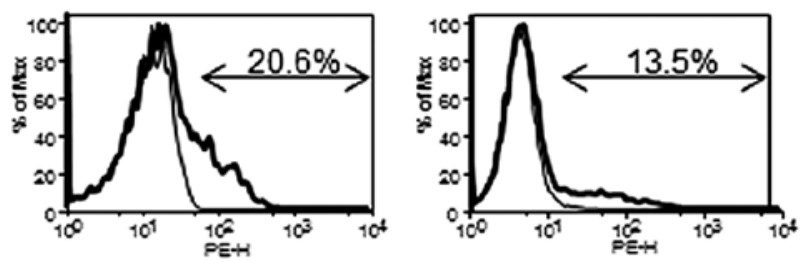

Anti-PD-1 Ab
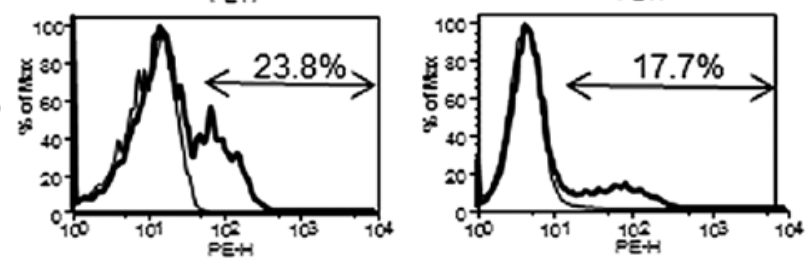

B Effect of anti-PD-1 antibody on IFN- $\gamma$ production

\begin{tabular}{lcc}
\hline Groups & $\mathrm{CD}^{+}{ }^{+} \mathrm{FN}-\gamma^{+}(\%)$ & $\mathrm{CD}^{+} \mathrm{IFN}-\gamma^{+}(\%)$ \\
\hline Control Ab & $45.5 \pm 14.2$ & $20.9 \pm 4.9$ \\
Control Ab+sPD-L1 & $39.7 \pm 13.8$ & $18.1 \pm 4.5$ \\
Anti-PD-1 Ab+sPD-L1 & $45.9 \pm 16.8$ & $22.4 \pm 5.6$
\end{tabular}


A

Control
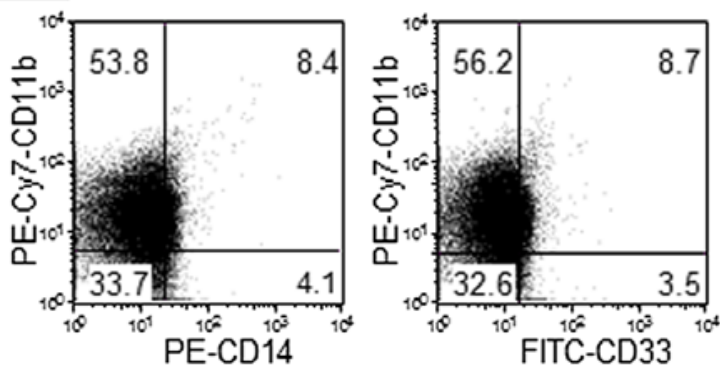

Anti-PD-1 Ab

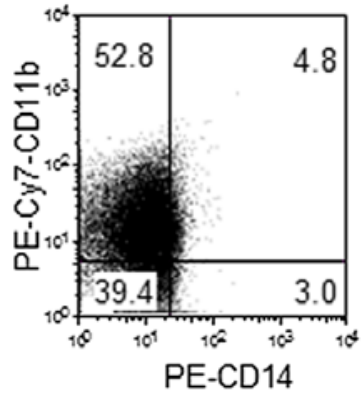

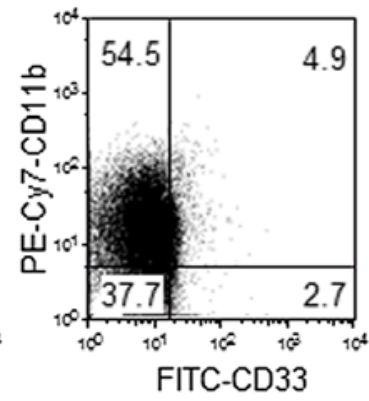

B

Effect of anti-PD-1 antibody on MDSC induction

\begin{tabular}{ccc}
\hline Groups & Control Ab (\%) & Anti-PD-1 Ab (\%) \\
\hline CD14 $^{+} \mathrm{CD} 11 \mathrm{~b}^{+}$ & $4.4 \pm 2.5$ & $2.7 \pm 1.5^{\star}$ \\
$\mathrm{CD}^{*} 3^{+} \mathrm{CD} 11 \mathrm{~b}^{+}$ & $4.7 \pm 2.3$ & $3.3 \pm 1.3$ \\
\hline
\end{tabular}

Each value shows mean \pm SD of PBMC data derived from 6 glioma patients. ${ }^{*} ; P=0.0489$
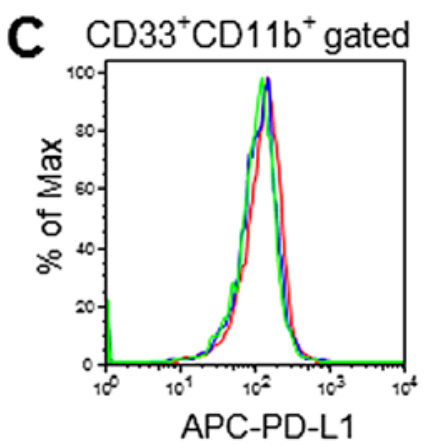

PD-1 Ab:

$A-0 \mu \mathrm{g} / \mathrm{ml}$

$\mathrm{B}-10 \mu \mathrm{g} / \mathrm{ml}$

$\mathrm{C}-20 \mu \mathrm{g} / \mathrm{ml}$

Figure 5. Inhibitory effect of anti-PD-1 mAb on MDSC induction in anti-CD3 Ab-stimulated PBMCs. (A) Reduction in CD33 ${ }^{+} \mathrm{CD} 11 \mathrm{~b}^{+} \mathrm{MDSC}^{\mathrm{And}} \mathrm{CD} 14^{+} \mathrm{CD} 11 \mathrm{~b}^{+}$ monocyte MDSC numbers by anti-PD-1 mAb. The flow cytometry data show a representative case from 6 sets of glioma patient-derived PBMCs. Each value indicates the frequency in \%. (B) The frequency of CD33 ${ }^{+} \mathrm{CD} 11 \mathrm{~b}^{+}$and $\mathrm{CD} 14^{+} \mathrm{CD} 11 \mathrm{~b}^{+}$MDSCs with or without anti-PD-1 mAb. (C) PD-L1 expression in $\mathrm{CD}_{3}{ }^{+} \mathrm{CD} 11 \mathrm{~b}^{+} \mathrm{MDSC}$ from PBMCs treated with various concentrations of anti-PD-1 mAb.

Table III. Effect of anti-PD-1 Ab on tumor antigen-specific CTL inductions.

$\mathrm{CD}^{+}$tetramer $^{+}$cell $(\%)$

\begin{tabular}{lcccc}
\cline { 2 - 5 } $\begin{array}{l}\text { Patient/ } \\
\text { tetramer }\end{array}$ & MART-1 & GP100 & CMVpp65 & A2 HIV A24 \\
\hline GB-001 & $0.02^{\mathrm{b}} / 0.39^{\mathrm{a}, \mathrm{c}}$ & $0.16 / 0.26^{\mathrm{a}}$ & $0.01 / 0.01$ & $0 / 0.01$ \\
GB-002 & $0.01 / 0.01$ & $0.02 / 0.74^{\mathrm{a}}$ & $0.02 / 0.11^{\mathrm{a}}$ & $0 / 0.02$ \\
GB-004 & $0.02 / 0.12^{\mathrm{a}}$ & $0.15 / 0.27^{\mathrm{a}}$ & $0.09 / 0.17^{\mathrm{a}}$ & $0 / 0.02$ \\
GB-006 & $0.04 / 0.05$ & $0.05 / 0.06$ & $0.38 / 1.13^{\mathrm{a}}$ & $\mathrm{ND}$
\end{tabular}

Each value shows $\mathrm{CD}^{+}{ }^{+}$tetramer ${ }^{+}$cell frequency. ${ }^{\mathrm{a}}$ More than $0.1 \%$ of $\mathrm{CD}^{+}{ }^{+}$tetramer ${ }^{+}$cell frequency was rated as positive after treatment with anti-PD-1 Ab. ${ }^{\text {b}}$ Treated with control Ab. ${ }^{\circ}$ Treated with anti-PD-1 Ab. ND, not done.

FoxP $3^{+}$cells in gated $\mathrm{CD}^{+}{ }^{+} \mathrm{CD} 25^{+}$fraction was inhibited in anti-PD-1 Ab-treated cultures (Fig. 6C).

\section{Discussion}

Since the development of anti-CTLA-4 Ab, ipilimumab has been administered to metastatic melanoma patients as an anti-check-point Ab $(1,16)$. More immunomodulatory Abs such as anti-PD-1 (3,17), anti-PD-L1 (4), anti-CD137 (18) and anti-CD40 $(19,20)$ have been developed and may be applicable to various advanced cancers. Ipilimumab treatment resulted in $>20 \%$ responders; in addition, the antibody resulted in long-term survival in metastatic melanoma patients despite adverse effects $(1,2)$. Remarkably, combination therapy with ipilimumab and nivolumab has shown great success in phase III clinical trials, with $>50 \%$ response rate $(21,22)$.

Intensive search for suitable biomarkers has been performed to enable responder prediction prior to treatment. This search uncovered blood biomarkers such as an increase in lymphocyte number, a decrease in LDH and MDSC numbers, and intratumoral biomarkers such as an increase in infiltrating $\mathrm{CD}^{+} \mathrm{T}$ cell numbers and granzyme and a decrease in regulatory $\mathrm{T}$ cell numbers $(23,24)$.

Similarly to ipilimumab, nivolumab has been reported to show a remarkable antitumor response and survival benefit in advanced melanoma and non-small cell lung cancer patients; however, the antibody was also found to induce autoimmune effects in thyroid and lung cancer patients in a phase III clinical trial $(22,25,26)$. With regard to biomarkers, genetic and cytokine markers have been intensively investigated using $\mathrm{T}$ cells and monocytes derived from cancer patients who have been treated with a combination of ipilimumab and nivolumab. These investigations demonstrated an increase in $\mathrm{T}$ cell proliferation, as well as upregulation of chemokine and NK cell function-associated genes (27).

Clinical trial studies demonstrated that a heterogeneous response to antibody therapy is expected for individuals, and the prediction of response will be difficult in spite of strong biomarkers. For this reason, the direct observation of the $\mathrm{PBMC}$ response to $\mathrm{Ab}$ treatment on an individual basis would 
A

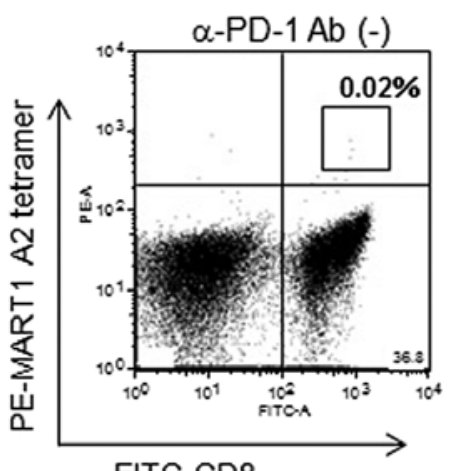

FITC-CD8
D

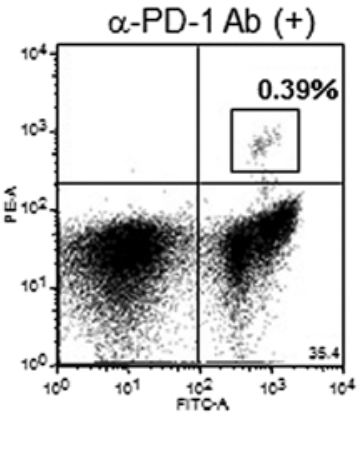

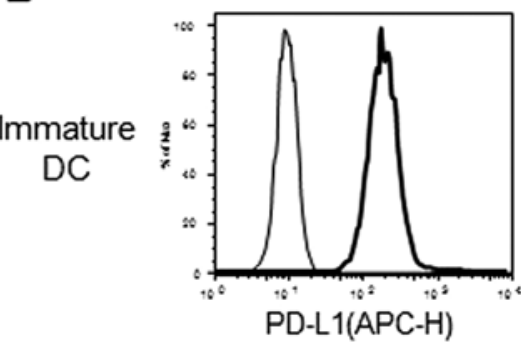

Mature

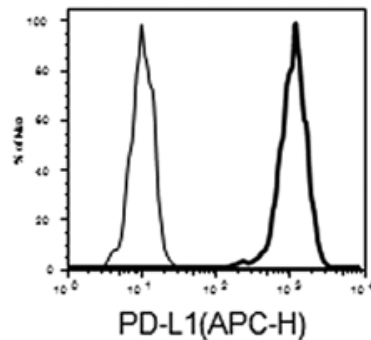

B

Effect of anti-PD-1 antibody on CTL induction

\begin{tabular}{ccccc}
\hline Group/tetramer & MART-1 & GP100 & $\begin{array}{r}\text { CMV } \\
\text { pp65 }\end{array}$ & HIV-1-A24 \\
\hline $\begin{array}{l}\text { CD8 }^{+} \text {tetramer } \\
\text { positive case\# }\end{array}$ & $2 / 4$ & $3 / 4$ & $3 / 4$ & $0 / 4$ \\
\hline
\end{tabular}

More than $0.1 \%$ of $\mathrm{CD}^{+}{ }^{+}$tetramer ${ }^{+}$cell frequency was rated as positive after treatment with anti-PD-1 Ab.

Effect of anti-PD-1 antibody on Treg induction

\begin{tabular}{lcc}
\hline \multicolumn{1}{c}{ Groups } & Control Ab (\%) & Anti-PD-1 Ab (\%) \\
\hline $\mathrm{CD}^{+} \mathrm{CD} 25^{+}$ & $6.1 \pm 0.8$ & $5.1 \pm 1.5$ \\
FoxP3 $^{+} / \mathrm{CD} 4^{+} \mathrm{CD} 25^{+}$ & $5.8 \pm 3.3$ & $3.1 \pm 2.2^{*}$ \\
\hline Each value shows mean $\pm \mathrm{SD}$ of PBMC data derived from 6 \\
glioma patients. CD $4^{+} \mathrm{CD} 25^{+}$fraction was gated and Foxp3 \\
cells were measured. ${ }^{*} ; P=0.045$
\end{tabular}

Figure 6. Effect of anti-PD-1 mAb on tumor antigen-specific CTL and Treg induction. (A) CD8 ${ }^{+}$MART-1 A2-tetramer ${ }^{+}$CTLs induction using mature DCs Mature type-1 DCs were induced by a combination of cytokines such as TNF $\alpha$, IL-1 $\beta$, IFN- $\alpha$, IFN- $\gamma$ plus poly I/C. Isotype control antibody or anti-PD-1 $\mathrm{mAb}$ was added to CTL cultures at $10 \mu \mathrm{g} / \mathrm{ml}$. Flow cytometry data indicate a representative case from 4 sets of glioma patient-derived PBMCs. (B) CD8 ${ }^{+}$ A2-tetramer ${ }^{+}$CTL-positive case numbers of total 4 cases are shown. The tetramers for MART-1, GP100 and CMVpp65 were HLA-A2-restricted, and HIV-1 tetramer was HLA-A24 restricted. (C) The frequencies of $\mathrm{CD}^{+} \mathrm{CD}^{+} 5^{+}$and $\mathrm{FoxP} 3^{+}$of $\mathrm{CD} 4{ }^{+} \mathrm{CD} 25^{+}$with or without anti-PD-1 mAb are shown. (D) PD-L1 expression on immature or mature DCs. Thin line, isotype control antibody; thick line, anti-PD-L1 mAb.

be helpful for predicting the immunological response for the patients in question. A substantial amount of evidence from many clinical trials has accumulated on this subject. However, in vitro research using nivolumab has not been extensively performed. In this study, we manufactured a biosimilar mAb to nivolumab in-house and evaluated its biological function using specific immunological assays. SPR analysis showed that our anti-PD-1 antibody had a $\mathrm{K}_{\mathrm{D}}$ value of $13.8 \mathrm{nM}$, and that of nivolumab is $3.06 \mathrm{nM}$ (28). Our in-house anti-PD-1 antibody seems to have a greater affinity than other commercially available anti-PD-1 monoclonal antibodies (98.9 nM, data not shown).

Wang et al (28) demonstrated that nivolumab showed simulatory activity in in vitro experiments, such as in MLR assays and cytokine production experiments; three positive observations were verified: i) $\mathrm{T}$ cell growth was stimulated and IFN- $\gamma$ production increased in co-culture with allogeneic dendritic cells (DCs), ii) regulatory $\mathrm{T}$ cell-mediated $\mathrm{T}$ cell growth inhibition was reversed, and iii) a synergistic increase in specific antibody titer after antigen vaccination in non-human primate resulted. However, no in vitro antibodydependent cell cytotoxicity was detected when nivolumab was used against activated $\mathrm{T}$ cells.

In this study, our anti-PD-1 antibody stimulated the proliferation of $\mathrm{T}$ cells activated with anti-CD3 antibody even at high antibody concentration in only a few cases $(20 \mu \mathrm{g} / \mathrm{ml})$. In particular, anti-PD-1 antibody restored the PD-L1-mediated $\mathrm{T}$ cell growth inhibition. These observations are consistent with those in previous studies.

Regarding the MDSC induction by anti-CD3 antibody stimulation, anti-PD-1 antibody inhibited MDSC induction in response to anti-CD3 antibody-stimulated PBMCs. The MDSC populations, $\mathrm{CD} 33^{+} \mathrm{CD} 11 \mathrm{~b}^{+}$and $\mathrm{CD} 14^{+} \mathrm{CD} 11 \mathrm{~b}^{+}$, are reported to be induced in the peripheral blood of cancer patients treated with chemotherapy $(29,30)$. The inhibitory effect shown by the anti-PD-1 antibody on MDSC induction represents the first report in the study of the immuno-logical function of the anti-PD-1 antibody using human PBMCs. 
In the near future, the effect of anti-PD-1 antibody on the MDSC inhibitory action on immune cells should be investigated to clarify the mechanism of antitumor effect of anti-PD-1 antibody.

Similarly, regulatory $\mathrm{T}$ cell induction mediated by mature DCs was suppressed by the addition of anti-PD-1 antibody in CTL induction cultures. Wang et al, Klein et al and Wong et al emphasized the restorative activity of the anti-PD-1 antibody on the regulatory $\mathrm{T}$ cell-mediated inhibition of effector $\mathrm{T}$ cell activation and cytokine production $(7,28,31,32)$. These observations that the anti-PD-1 antibody reversed the immunological inhibition by regulatory $\mathrm{T}$ cells and MDSCs in vitro, suggest that the anti-PD-1 antibody induces antitumor activity by restoring the immunosuppressive state and by activating $\mathrm{T}$ cell function.

Importantly, DC-mediated antigen-specific CTL induction was potentiated more efficiently in the presence of the anti-PD-1 antibody. Therefore, this observation suggests that it may be beneficial to develop a combined anti-PD-1 antibody and DC vaccine as a therapy $(33,34)$.

Finally, to develop an anti-PD-1 antibody therapy model that is more significant than in vitro studies, we have developed an autologous immunotherapy in vivo model based on humanized NOG mice (35), in which both the autologous immune system and autologous tumors can be established. This autologous immunotherapy in vivo model will next be used to predict the immunological effect in cancer patients who will receive anti-PD-1 antibody therapy.

\section{Acknowledgements}

This study was supported by a grant to Yasuto Akiyama by JSPS KAKENHI (grant no. 25430166), Japan.

\section{References}

1. Weber JS, O'Day S, Urba W, Powderly J, Nichol G, Yellin M, Snively J and Hersh E: Phase I/II study of ipilimumab for patients with metastatic melanoma. J Clin Oncol 26: 5950-5956, 2008.

2. Hodi FS, O'Day SJ, McDermott DF, Weber RW, Sosman JA, Haanen JB, Gonzalez R, Robert C, Schadendorf D, Hassel JC, et al: Improved survival with ipilimumab in patients with metastatic melanoma. N Engl J Med 363: 711-723, 2010.

3. Topalian SL, Hodi FS, Brahmer JR, Gettinger SN, Smith DC, McDermott DF, Powderly JD, Carvajal RD, Sosman JA, Atkins MB, et al: Safety, activity, and immune correlates of anti-PD-1 antibody in cancer. N Engl J Med 366: 2443-2454, 2012.

4. Brahmer JR, Tykodi SS, Chow LQ, Hwu WJ, Topalian SL, Hwu P, Drake CG, Camacho LH, Kauh J, Odunsi K, et al: Safety and activity of anti-PD-L1 antibody in patients with advanced cancer. N Engl J Med 366: 2455-2465, 2012.

5. Wolchok JD, Kluger H, Callahan MK, Postow MA, Rizvi NA, Lesokhin AM, Segal NH, Ariyan CE, Gordon RA, Reed K, et al: Nivolumab plus ipilimumab in advanced melanoma. $\mathrm{N}$ Engl J Med 369: 122-133, 2013.

6. Pericord VA, Montalvo W, Leiner IM and Allison JP: Single dose of anti-CTLA-4 enhances CD8 T-cell memory formation, function, and maintenance. Proc Natl Acad Sci USA 108: 261-271 2011.

7. Wang W, Lau R, Yu D, Zhu W, Korman A and Weber J: PD1 blockade reverses the suppression of melanoma antigen-specific CTL by $\mathrm{CD}^{+}{ }^{+} \mathrm{CD} 25(\mathrm{Hi})$ regulatory $\mathrm{T}$ cells. Int Immunol 21: 1065-1077, 2009.

8. Sznol M and Chen L: Antagonist antibodies to PD-1 and B7-H1 (PD-L1) in the treatment of advanced human cancer. Clin Cancer Res 19: 1021-1034, 2013.

9. Okazaki T, Chikuma S, Iwai Y, Fagarasan S and Honjo T: A rheostat for immune responses: The unique properties of PD-1 and their advantages for clinical application. Nat Immunol 14: 1212-1218, 2013.
10. Weber JS, D'Angelo SP, Minor D, Hodi FS, Gutzmer R, Neyns B, Hoeller C, Khushalani NI, Miller WH Jr, Lao CD, et al: Nivolumab versus chemotherapy in patients with advanced melanoma who progressed after anti-CTLA-4 treatment (CheckMate 037): A randomised, controlled, open-label, phase 3 trial. Lancet Oncol 16: 375-384, 2015.

11. John LB, Devaud C, Duong CP, Yong CS, Beavis PA, Haynes NM, Chow MT, Smyth MJ, Kershaw MH and Darcy PK: Anti-PD-1 antibody therapy potently enhances the eradication of established tumors by gene-modified $\mathrm{T}$ cells. Clin Cancer Res 19: 5636-5646, 2013.

12. Mangsbo SM, Sandin LC, Anger K, Korman AJ, Loskog A and Tötterman TH: Enhanced tumor eradication by combining CTLA-4 or PD-1 blockade with CpG therapy. J Immunother 33: 225-235, 2010.

13. Nakamura Y, Tai S, Oshita C, Iizuka A, Ashizawa T, Saito S, Yamaguchi S, Kondo H, Yamaguchi K and Akiyama Y: Analysis of HLA-A24-restricted peptides of carcinoembryonic antigen using a novel structure-based peptide-HLA docking algorithm. Cancer Sci 102: 690-696, 2011.

14. Akiyama Y, Komiyama M, Nakamura Y, Iizuka A, Oshita C, Kume A, Nogami M, Miyata H, Ashizawa T, Yoshikawa $\mathrm{S}$, et al: Identification of novel MAGE-A6- and MAGE-A12derived HLA-A24-restricted cytotoxic T lymphocyte epitopes using an in silico peptide-docking assay. Cancer Immunol Immunother 61: 2311-2319, 2012.

15. Iizuka A, Komiyama M, Oshita C, Kume A, Ashizawa T, Mitsuya K, Hayashi N, Nakasu Y, Yamaguchi K and Akiyama Y: Anti-vascular endothelial growth factor receptor (VEGFR) 2 autoantibody identification in glioblastoma patient using single B cell-based antibody gene cloning. Immunol Lett 159: 15-22, 2014.

16. Callahan MK, Wolchok JD and Allison JP: Anti-CTLA-4 antibody therapy: Immune monitoring during clinical development of a novel immunotherapy. Semin Oncol 37: 473-484, 2010.

17. Topalian SL, Sznol M, McDermott DF, Kluger HM, Carvajal RD, Sharfman WH, Brahmer JR, Lawrence DP, Atkins MB, Powderly JD, et al: Survival, durable tumor remission, and long-term safety in patients with advanced melanoma receiving nivolumab. J Clin Oncol 32: 1020-1030, 2014.

18. Ascierto PA, Simeone E, Sznol M, Fu YX and Melero I: Clinical experiences with anti-CD137 and anti-PD1 therapeutic antibodies. Semin Oncol 37: 508-516, 2010.

19. Vonderheide RH, Flaherty KT, Khalil M, Stumacher MS Bajor DL, Hutnick NA, Sullivan P, Mahany JJ, Gallagher M, Kramer A, et al: Clinical activity and immune modulation in cancer patients treated with CP-870,893, a novel CD40 agonist monoclonal antibody. J Clin Oncol 25: 876-883, 2007.

20. Melero I, Grimaldi AM, Perez-Gracia JL and Ascierto PA: Clinical development of immunostimulatory monoclonal antibodies and opportunities for combination. Clin Cancer Res 19: 997-1008, 2013.

21. Mahoney KM, Freeman GJ and McDermott DF: The next immune-checkpoint inhibitors: PD-1/PD-L1 blockade in melanoma. Clin Ther 37: 764-782, 2015.

22. Larkin J, Chiarion-Sileni V, Gonzaliz R, Grob JJ, Cowey CL, Lao CD, Schadendorf D, Dummer R, Smylie M, Rutkowski P, et al: Combined nivolumab and ipilimumab or monotherapy in untreated melanoma. N Engl J Med 373: 23-34, 2015.

23. Ascierto PA, Kalos M, Schaer DA, Callahan MK and Wolchok JD: Biomarkers for immunostimulatory monoclonal antibodies in combination strategies for melanoma and other tumor types. Clin Cancer Res 19: 1009-1020, 2013.

24. Simeone E, Gentilcore G, Giannarelli D, Grimaldi AM, Caracò C, Curvietto M, Esposito A, Paone M, Palla M, Cavalcanti $\mathrm{E}$, et al: Immunological and biological changes during ipilimumab treatment and their potential correlation with clinical response and survival in patients with advanced melanoma. Cancer Immunol Immunother 63: 675-683, 2014.

25. Brahmer J, Reckamp KL, Baas P, Crino L, Eberhardt WE, Poddubskaya E, Antonia S, Pluzanski A, Vokes EE, Holgado E et al: Nivolumab versus docetaxel in advanced squamous-cell non-small-cell lung cancer. N Engl J Med 373: 123-135. 2015.

26. Rizvi NA, Mazières J, Planchard D, Stinchcombe TE, Dy GK, Antonia SJ, Horn L, Lena H, Minenza E, Mennecier B, et al: Activity and safety of nivolumab, an anti-PD-1 immune checkpoint inhibitor, for patients with advanced, refractory squamous non-small-cell lung cancer (CheckMate 063): A phase 2, single-arm trial. Lancet Oncol 16: 257-265, 2015. 
27. Das R, Verma R, Sznol M, Boddupalli CS, Gettinger SN, Kluger H, Callahan M, Wolchok JD, Halaban R, Dhodapkar $\mathrm{MV}$, et al: Combination therapy with anti-CTLA-4 and anti-PD-1 leads to distinct immunologic changes in vivo. J Immunol 194: 950-959, 2015.

28. Wang C, Thudium KB, Han M, Wang XT, Huang H, Feingersh D, Garcia C, Wu Y, Kuhne M, Srinivasan M, et al In vitro characterization of the anti-PD-1 antibody nivolumab, BMS-936558, and in vivo toxicology in non-human primates. Cancer Immunol Res 2: 846-856, 2014.

29. Jiang J, Guo W and Liang X: Phenotypes, accumulation, and functions of myeloid-derived suppressor cells and associated treatment strategies in cancer patients. Hum Immunol 75: 1128-1137, 2014.

30. Markowitz J, Brooks TR, Duggan MC, Paul BK, Pan X, Wei L, Abrams Z, Luedke E, Lesinski GB, Mundy-Bosse B, et al Patients with pancreatic adenocarcinoma exhibit elevated levels of myeloid-derived suppressor cells upon progression of disease. Cancer Immunol Immunother 64: 149-159, 2015.

31. Klein O, Ebert LM, Nicholaou T, Browning J, Russell SE, Zuber M, Jackson HM, Dimopoulos N, Tan BS, Hoos A, et al: Melan-A-specific cytotoxic T cells are associated with tumor regression and autoimmunity following treatment with antiCTLA-4. Clin Cancer Res 15: 2507-2513, 2009.
32. Wong RM, Scotland RR, Lau RL, Wang C, Korman AJ, Kast WM and Weber JS: Programmed death-1 blockade enhances expansion and functional capacity of human melanoma antigen-specific CTLs. Int Immunol 19: 1223-1234, 2007.

33. Weber JS, Kudchadkar RR, Yu B, Gallenstein D, Horak CE, Inzunza HD, Zhao X, Martinez AJ, Wang W, Gibney G, et al: Safety, efficacy, and biomarkers of nivolumab with vaccine in ipilimumab-refractory or -naïve melanoma. J Clin Oncol 31: 4311-4318, 2013.

34. Ribas A, Comin-Anduix B, Chmielowski B, Jalil J, de la Rocha P, McCannel TA, Ochoa MT, Seja E, Villanueva A, Oseguera DK, et al: Dendritic cell vaccination combined with CTLA4 blockade in patients with metastatic melanoma. Clin Cancer Res 15: 6267-6276, 2009.

35. Inoue M, Senju S, Hirata S, Irie A, Baba $H$ and Nishimura Y: An in vivo model of priming of antigen-specific human CTL by Mo-DC in NOD/Shi-scid IL2rgamma(null) (NOG) mice. Immunol Lett 126: 67-72, 2009. 